\title{
CORRELATION OF HOURLY SUCTION TRAP COLLECTIONS OF CULICOIDES FURENS AND C. HOLLENSIS (DIPTERA: CERATOPOGONIDAE) WITH WIND, TEMPERATURE AND HABITAT ${ }^{1}$
}

\author{
By H. G. Koch ${ }^{2,3}$ and R. C. Axtell ${ }^{2}$
}

\begin{abstract}
Daily flight activity of Culicoides furens and C. hollensis was monitored during peak seasonal abundance near salt marsh breeding sites by hourly collections with suction traps. Both species had 2 crepuscular peaks of activity. C. furens was mostly nocturnal, with a large peak of activity immediately after sunset; $C$. hollensis was mostly diurnal with a large morning peak. Males accounted for only $9 \%$ of the C. furens and $3 \%$ of the $C$. hollensis total catches. Wind (velocity and direction) and temperature were continuously measured during the hours of suction trap operation and correlated with insect capture. $C$. furens activity was correlated with wind velocity. C. hollensis activity was correlated with wind direction and temperature. Many more $C$. furens specimens were trapped in the marsh than in the adjacent wooded area; $C$. hollensis adults were trapped about equally in the 2 areas. $C$. furens remained active throughout the day in the wooded area but not in the marsh.
\end{abstract}

The biting midges Culicoides furens (Poey) and $C$. hollensis (Melander \& Brues) are often found in large numbers along the Eastern and Gulf coasts of the United States where they breed in salt marshes. The adults attack man and animals, causing a severe nuisance and a significant impact on development and tourism (review: Linley \& Davies 1971).

Biting counts have been the principal method used to study the flight activity of Culicoides (Kettle 1977, Kettle \& Linley 1969a, b, Snow 1955). In Jamaica, C. furens showed continuous biting activity throughout the night with peaks at 2100 and $2400 \mathrm{~h}$ (Kettle 1969a). Temperature and wind speed (Kettle 1969b) were more important meteorological factors than illumination and saturation deficit in modifying the 24-h endogenous biting cycle of $C$. furens. The seasonal effects on the biting habits of $C$. furens and the importance of various

\footnotetext{
${ }^{1}$ This research was supported by NOAA, Office of Sea Grant, U.S. Department of Commerce, under Grant No. 94-3-158-40 and the North Carolina Department of Administration. Paper No. 5476 of the Journal Series of the North Carolina Agricultural Experiment Station.

${ }^{2}$ Department of Entomology, North Carolina State University, Raleigh, North Carolina 27607, USA.

${ }^{3}$ Present address: Lone Star Tick Laboratory, USDA, ARS, P. O. Box 588, Poteau, Oklahoma 24953, USA.
}

factors on the biting rate were summarized by Kettle (1972).

Flight and biting activity are often poorly correlated, as has been demonstrated for $C$. furens (Bidlingmayer 1961) and C. variipennis (Coquillett) (Nelson \& Bellamy 1971). The use of suction traps to measure flight activity of Culicoides has been advocated due to their nonattractancy (Kettle 1962) and these were used by Reuben (1963), Lewis \& Taylor (1965) and Service (1971, 1974). Since stationary traps may be visually attractive to the insects, the type of suction trap (review: Service 1976) may influence the qualitative and quantitative sampling of the adult hematophagous insects.

We measured the flight activity of adults of $C$. furens and $C$. hollensis using suction traps positioned in and adjacent to a salt marsh known to be a prolific breeding area for those species. The objectives were to (1) determine flight activity cycles during periods of peak seasonal abundance, (2) determine any correlations between flight activity and temperature, wind speed and direction, and (3) compare flight activity in an open marsh with that in an adjacent wooded area.

\section{MATERIALS AND METHODS}

\section{Study area}

These studies were conducted in and adjacent to a Spartina alterniflora Loiseleur-dominated salt marsh along the Newport River at the end of Lake Shore Drive, Morehead City, North Carolina during the spring and summer of 1976. C. furens was found breeding throughout the Spartina marsh, especially in the areas of short $(<0.3 \mathrm{~m}) S$. alterniflora, but $C$. hollensis was found predominantly in the areas of tall $(>1.3 \mathrm{~m}) \mathrm{S}$. alterniflora along the major drainage ditches (Kline \& Axtell 1977). A dense hardwood forest was adjacent to much of the marsh on the upland, but in 1 area a large open field was separated from the marsh by only a narrow (12-15 m) area of trees and shrubs. 
TABle 1. Significance levels* (multiple regression analysis) of parameters related to hourly catches of adult Culicoides furens and C. hollensis by a suction trap in a Spartina salt marsh and in a nearby wooded area.

\begin{tabular}{|c|c|c|c|c|c|c|c|}
\hline \multirow[b]{2}{*}{ Parameter } & \multicolumn{3}{|c|}{ TRAP ON MARSH } & \multicolumn{3}{|c|}{ TRAP IN WOODED BORDER } & \multirow{2}{*}{$\begin{array}{r}\text { TOTAL CATCH } \\
\text { BOTH TRAPS } \\
\end{array}$} \\
\hline & $\delta$ & $q$ & 89 & $\delta$ & $q$ & ơ & \\
\hline \multicolumn{8}{|l|}{ Culicoides furens } \\
\hline Wind velocity & 0.005 & 0.05 & 0.05 & NS & 0.005 & 0.005 & 0.01 \\
\hline Wind direction & NS & NS & NS & 0.001 & 0.005 & 0.005 & NS \\
\hline \multicolumn{8}{|l|}{ Culicoides hollensis } \\
\hline Minimum temperature & 0.0001 & 0.0001 & 0.0001 & NS & 0.01 & 0.01 & 0.0001 \\
\hline Wind direction & 0.0001 & 0.0001 & 0.0001 & NS & 0.05 & 0.05 & 0.0001 \\
\hline Average temperature & 0.0001 & 0.0001 & 0.0001 & NS & NS & NS & 0.0001 \\
\hline Maximum temperature & 0.01 & 0.005 & 0.005 & NS & NS & NS & 0.005 \\
\hline
\end{tabular}

$*$ NS $=$ Not significant.

\section{Methods of collection}

Adult Culicoides were trapped by 2 identical AC suction traps capable of segregating catches into hourly samples (Koch et al. 1977). Flying insects were drawn into a collecting funnel by air currents from a horizontally mounted fan about $1.8 \mathrm{~m}$ above the ground. Captured insects were blown down the collecting funnel and into alcohol in glass jars mounted in a turntable. The 12 jars rotated 1 position each hour and were all collected after 12 $\mathrm{h}$ for identification and counting of Culicoides.

One trap was positioned about $10 \mathrm{~m}$ into the marsh from the edge of the narrow shrub-tree zone separating the marsh and open field. The site was irregularly flooded and did not produce large numbers of Culicoides. The other trap was positioned $15 \mathrm{~m}$ away in the center of a small path (2 $m$ wide) running parallel to the marsh edge and within the narrow shrub-tree zone. The latter trap was somewhat more protected from the wind and partially shaded at times but not visible from the marsh. The nearest significant breeding areas for C. furens and C. hollensis, as determined previously by Kline \& Axtell (1977), were 10-15 m from the traps.

Traps were operated a total of $444 \mathrm{~h}$ on certain days during March-August to correspond with periods of peak abundance of either C. hollensis or C. furens (Kline \& Axtell 1976). The difference in daily activity of $C$. furens (primarily nocturnal) and C. hollensis (primarily diurnal) necessitated different sampling times for the 2 species. C. furens was sampled on 3 days from 0700 to $1900 \mathrm{~h}$ and 12 days from 1900 to $0700 \mathrm{~h}$, while C. hollensis was sampled on 15 days from 0700 to $1900 \mathrm{~h}$ and 9 days from 1900 to $0700 \mathrm{~h}$. Eastern standard time is used in this report.

\section{Meteorological data}

The wind velocity and direction were measured by a $12-V$ DC windset/windvane and 3-cup anemometer. The recorder was calibrated $0-31 \mathrm{~km} / \mathrm{h}$ windspeed and $0-360^{\circ}$ azimuth. The rotating anemometer cups and weather vane were located 1.8 $\mathrm{m}$ above ground and $5 \mathrm{~m}$ from the suction trap in the salt marsh. Wind velocity around the upland trap was somewhat reduced by the vegetation acting as a partial barrier.

Air temperature $\left({ }^{\circ} \mathrm{C}\right)$ was monitored continuously by a shaded thermistor ( $1.8 \mathrm{~m}$ above the gound) and recorder located $35 \mathrm{~m}$ from the traps in another part of the salt marsh. The upland trap was partially shaded at certain times of the day by the canopy layer.

\section{Data analysis}

The average temperature, the average minimum and maximum temperature, and the average wind speed were calculated for each hour. The predominant wind direction for each hour was recorded and assigned to the nearest directional unit (i.e., N, NNE, NE, ENE, E) created by dividing $360^{\circ}$ into 16 equal sectors.

The numbers of males and females captured at each of the 2 traps were subjected to regression analysis with the following parameters: Time, Time $\times$ Time $($ TSQ), Time $\times$ TSQ $($ TCUB), Direction (DIR), Average Wind Velocity (AWS), Average Temperature (AT), Minimum Temperature (MINT), and Maximum Temperature (MAXT). Those parameters which were significantly correlated ( $\leqslant 0.05$ level of probability) are shown in $\mathrm{T}_{\mathrm{A}}$ BLE 1 .

The activity curve for each species was deter- 

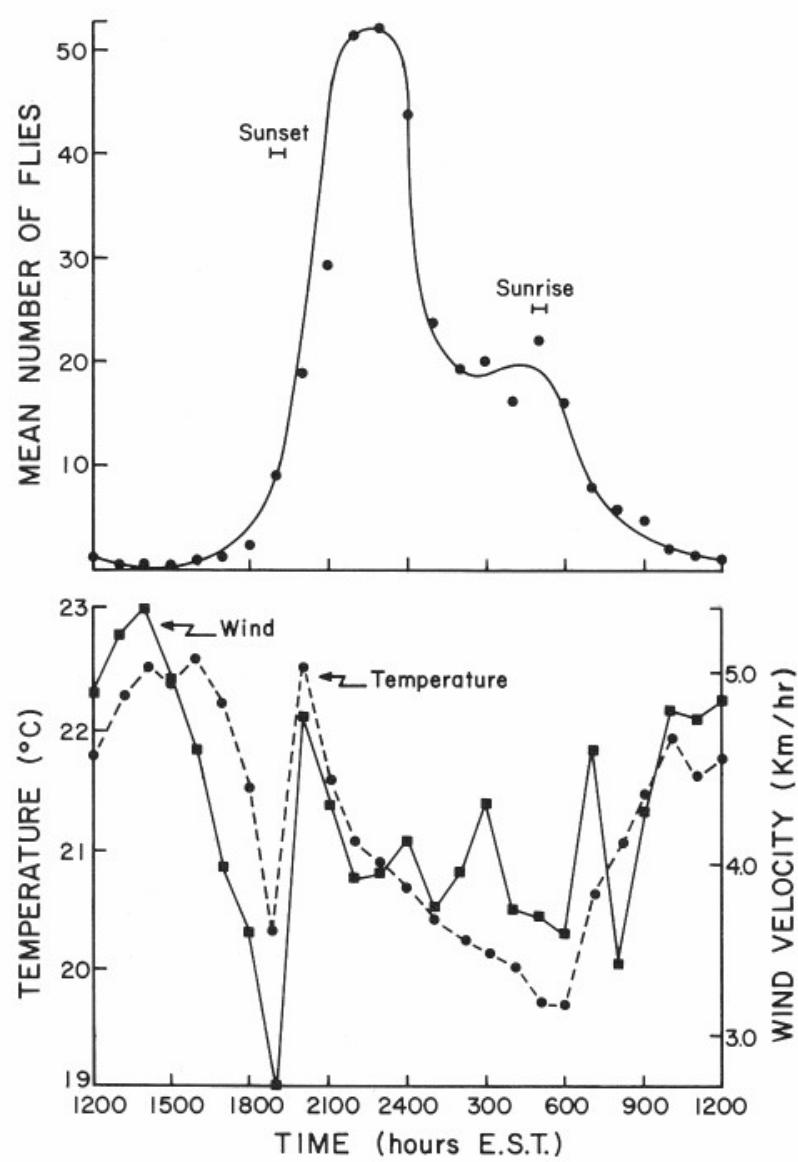

Fig. 1. Mean number of Culicoides furens collected per hour with suction traps in and near a Spartina salt marsh and the average hourly temperature and wind velocity.

mined by combining the total catch/hour of both traps, averaging catches for 3 consecutive hours (3 point moving average) and averaging the values of the same time periods over all collections. The means were graphed vs time (FIG. 1, 2). The average temperature and wind velocity were also plotted vs time.

\section{RESULTS AND DISCUSSION}

\section{Culicoides furens}

Two peaks of activity occurred during the 24-h period (FIG. 1). The largest peak was immediately after sunset and continued until midnight, followed by a rapid decline in activity. A much smaller peak occurred at sunrise, followed by a gradual decline in activity throughout the day, reaching a minimum at midafternoon. Bidlingmayer (1961), using truck-trap collections in Florida, found 2 peaks of activity around dusk and dawn for C. furens. Kettle (1969a) also found crepuscular activity for C. furens in Jamaica using biting counts. Both investigations showed a somewhat larger peak in the morning than evening. Our results also show that $C$. furens is primarily crepuscular and nocturnal but reveal a much larger evening peak than previously reported.

Of the 8084 flies trapped over $360 \mathrm{~h}$, about $9 \%$ were males. Kline \& Axtell (1976) found that 40$44 \%$ of the C. furens emerging from the marsh were males. Bidlingmayer (1961) did not include males in his truck-trap collections and Kettle (1969a) sampled only females. C. impunctatus (Goetghebuer) males were rarely taken with suction traps positioned near breeding grounds in Scotland (Reuben 1963). Service (1971) found few males $(<15 \%)$ of 4 species of Culicoides sampled similarly in a wooded area of England.

The trap in the marsh caught 6091 C. furens compared to 1993 captured within the wooded border section, with most of the specimens captured during the night. However, $85 \%$ of the total from $0900-1700 \mathrm{~h}$ was captured by the trap in the wooded area, indicating that $C$. furens remains more active (at least at the 1.8-m elevation sampled by the traps) during the day in the wooded area than in the marsh. Males were captured 4-5 times as frequently with the suction trap located in the marsh, indicating much more activity there than in the wooded area. Bidlingmayer (1961), using a power aspirator, found that C. furens males rested closer to the marsh breeding grounds than females and preferred trees more than females did. Our studies indicate that during the night, which is the period of greatest activity, both males and females are more active over the open marsh than in the wooded area (at the 1.8-m sampling elevation), but this is reversed during the daylight hours.

The wooded area provides a much more diverse and stable environment than the open marsh and, therefore, the elevation preference of the Culicoides is probably different for the 2 habitats. It is likely that adult Culicoides seek a particular vertical stratum, due to unknown factors (Henry \& Adkins 1975, Service 1971, Tanner \& Turner 1974), as soon as they enter a wooded area. Kline \& Axtell (1977), using sticky cylinder traps, found no difference in male or female captures at 0.6-, 1.2- and 1.8-m elevations within a Spartina salt marsh, but Bidlingmayer (1961) showed that C. furens males preferred 2.44 and $4.27 \mathrm{~m}$ and females 0.30 - and $0.61-m$ elevations within wooded areas. Cyclic vertical migrations, elevation preference and horizontal spreading within forest habitats have been 
shown for some other species of Culicoides (Snow 1955). Large numbers of C. furens have been taken with light traps in open and wooded areas at tree canopy levels (Breeland \& Smith 1962, Henry \& Adkins 1975) but these may have been atypical and due to the insects being windborne and/or attracted by the light traps.

Only wind velocity and direction, among parameters included in the analysis, significantly $(P \leqslant$ 0.05 ) affected females at the 2 trap locations ( $\mathrm{T}_{\mathrm{A}}$ BLE 1). There were fewer males trapped in the wooded area and the correlation with wind velocity was not significant. Wind direction was significant in the wooded area but not in the open marsh. Only $25 \%$ of the combined flight activity variability $\left(R^{2}=0.2470\right)$ was explained by including all the measured variables in the multiple regression analysis. This indicates that other parameters also have significant effects on the activity of C. furens. Average wind velocity was the only parameter to significantly affect the total catch of both traps. Decreasing winds during the afternoon were accompanied by increasing flight activity until shortly after sunset and into the night, when the wind increased to substantial levels (FIG. 1). Increasing winds after sunrise were accompanied by decreasing flight activity. Temperature (FIG. 1) did not change much during the experiments, which were conducted mostly in July, and consequently was not significantly correlated with the flight activity of $C$. furens. If low nighttime temperatures had occurred during the experiments, this parameter would probably have been significant.

Kettle (1969a, b) found that biting activity of $C$. furens was unaffected by wind velocities below 3.2 $\mathrm{km} / \mathrm{h}$ but ceased at $9.6 \mathrm{~km} / \mathrm{h}$. We collected a few specimens at windspeed of $12.2 \mathrm{~km} / \mathrm{h}$ (the greatest average windspeed) in both suction traps, but these may have been windborne. No activity thresholds were established in our study, but it appears that males and females were affected differently within the range of wind conditions encountered. Wind velocity was significant for females trapped in the wooded border and for both sexes in the marsh.

At low windspeeds $(<3.2 \mathrm{~km} / \mathrm{h}$ measured on the marsh), C. furens was more active at the $1.8-\mathrm{m}$ elevation (top of the suction traps) in the wooded area than in the open marsh. While the traps were operating, windspeeds $<3.2 \mathrm{~km} / \mathrm{h}$ occurred $25 \%$ of the time, during which $44 \%$ of the catch in the wooded area occurred and $12 \%$ of the catch in the marsh. With windspeeds of $3.2-5.0 \mathrm{~km} / \mathrm{h}$, which occurred $44 \%$ of the time, $45 \%$ of the catch in the wooded area occurred but $81 \%$ of the catch in the marsh. The large catch in the marsh apparently was due to more wind-borne Culicoides being carried over the suction trap and not a reflection of fly activity. At windspeeds $>5.0 \mathrm{~km} / \mathrm{h}$, which occurred $31 \%$ of the time, flight was inhibited and only $11 \%$ of the catch in the woods and $7 \%$ of the catch in the marsh occurred.

Wind direction, significant only in the wooded area catch, may be important in distributing host odors at low moderate wind velocities to unfed Culicoides in the marsh, thus stimulating flight toward the upland. Although the winds came mostly from the west ( $29 \%$ of the time) blowing toward a very small portion of marsh, these were relatively strong and resulted in poor fly capture. Weaker winds from the SE and SSE blowing toward the majority of the marsh resulted in greater fly capture, particularly in the woods.

\section{Culicoides hollensis}

Two peaks of activity of $C$. hollensis occurred during the 24-h period (FIG. 2). The largest peak was in the morning, with most activity during the daylight hours, which is the opposite of that for $C$. furens (FIG. 1). The morning outburst of activity for $C$. hollensis was much more distinct and shorter than the evening peak for either species. These studies indicate that $C$. hollensis is principally diurnal in activity, with a distinct and ephemeral peak of activity in the morning.

A total of 6718 flies were trapped over $576 \mathrm{~h}$, but only $3 \%$ were males. Kline \& Axtell (1976) found that $54-56 \%$ of the C. hollensis emerging from the adjacent marsh were males. It appears that even fewer males of this species are present at the $1.8-\mathrm{m}$ elevation, or perhaps they stay closer to the breeding sites.

The trap in the marsh caught 3757 flies compared to 2961 within the wooded border section. Males were captured nearly as often in the marsh as in the wooded area. C. hollensis individuals may not disperse as much as $C$. furens after entering the wooded area, or perhaps they fly upland more readily.

Temperature (minimum, maximum and average) and wind direction, among the parameters included in the analysis, significantly $(P \leqslant 0.05)$ affected the hourly catches of males and females at the 2 trap locations (TABLE 1). For the trap in the marsh the correlations were significant for each sex, but for the trap in the wooded area there 

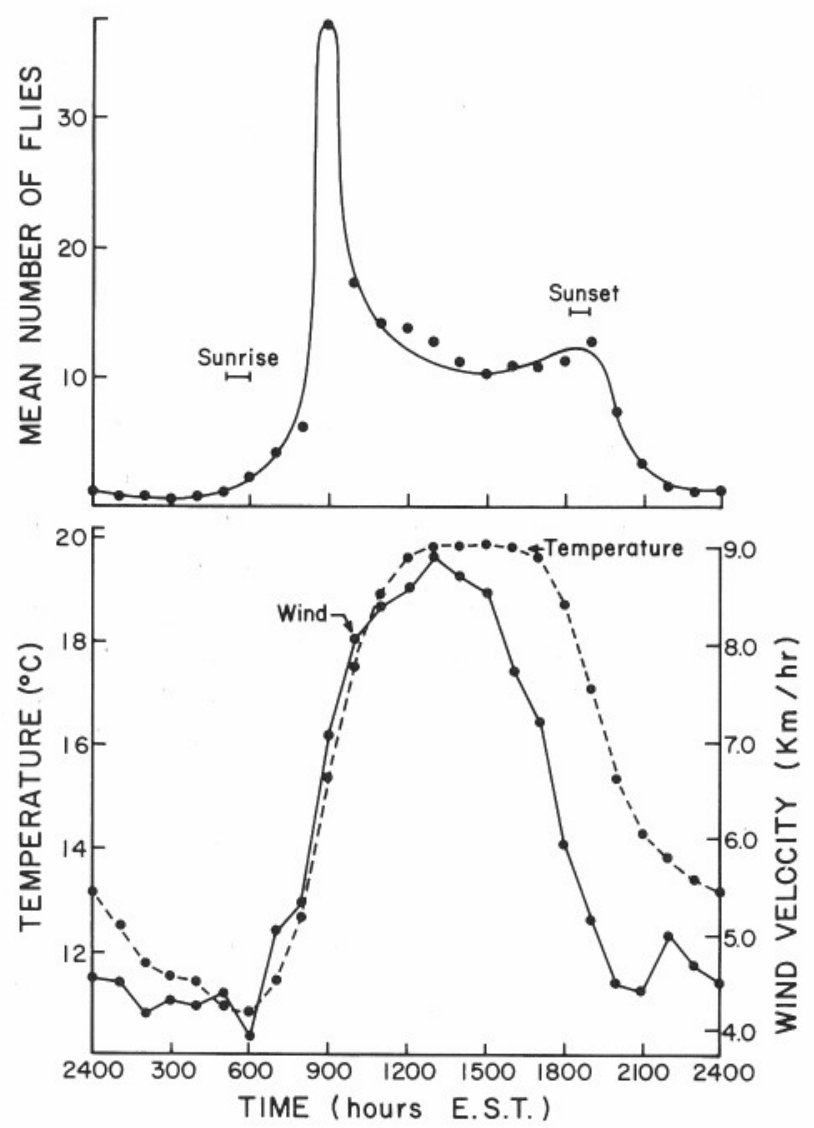

FIG. 2. Mean number of Culicoides hollensis collected per hour with suction traps in and near a Spartina salt marsh and the average hourly temperature and wind velocity.

were only significant correlations between catches of females and minimum temperature and wind direction. About $39 \%$ of the combined flight activity variability $\left(R^{2}=0.3914\right)$ was explained by including all the measured variables in the multiple regression analysis. This is a greater correlation coefficient than for $C$. furens and probably reflects the stressful early season low and variable temperatures and the wind. Temperature and wind direction were highly significant in determining total catch by the 2 traps. Average wind velocity was not as important as found for $C$. furens, possibly due to the much larger size of $C$. hollensis.

The average temperature and wind velocity in relation to the average hourly catches of $C$. hollensis are shown in FIG. 2. Peak activity occurred in the morning when the temperatures reached a favorable level, usually $1-2 \mathrm{~h}$ after sunrise. Activity leveled off during the warmest part of the day before the small sunset peak. Decreasing temperatures were then accompanied by decreasing activ- ity during the night. Temperatures during this early springtime often change dramatically and may be responsible for most of the observed behavior patterns. Studies on C. furens were conducted during the summer when hourly fluctuations in temperature were much less.

Insects trapped within the wooded border were not as affected by temperature changes as those trapped in the marsh (TABLE 1). The wooded site probably has a more stable microclimate due in part to the surrounding vegetation providing partial sun and wind barriers. One exceptionally large collection (1288 in the marsh, 85 in the woods) occurred early in the season (25 March) from $0700-0800 \mathrm{~h}$ with a moderate wind $(3.6 \mathrm{~km} / \mathrm{h}$ SSW) and a temperature change from $5.0^{\circ}-11.7^{\circ} \mathrm{C}$. Wind was thus blowing directly toward the major breeding area and the effect of the rapid hourly temperature change was greatest in the marsh.

Low temperatures $\left(<10^{\circ} \mathrm{C}\right)$ or strong winds $(>5.0 \mathrm{~km} / \mathrm{h})$ often accompanied a delay in the morning peak of activity. Little activity was observed before the ambient temperature reached $8^{\circ}-10^{\circ} \mathrm{C}$.

Low winds $(<3.2 \mathrm{~km} / \mathrm{h})$ occurred $31 \%$ of the time, primarily outside of peak activity periods $(2000-0500 \mathrm{~h})$ when lower temperatures probably restricted or prohibited flight. About $18 \%$ of the total woods catch and $26 \%$ of the marsh catch occurred at low wind speeds, mostly during daytime favorable temperatures. Moderate winds (3.2-5.0 $\mathrm{km} / \mathrm{h}$ ) occurred $28 \%$ of the time mostly during peak activity $(0600-1900 \mathrm{~h})$ when the temperatures favored insect flight. About $33 \%$ of the total woods catch and $55 \%$ of the marsh catch occurred at these wind speeds. High winds $(>5.0 \mathrm{~km} / \mathrm{h})$ predominated during the remaining $41 \%$ of the time, corresponding with $49 \%$ of the total woods catch but only $19 \%$ of the total marsh catch. It appeared that the stronger winds resulted in greater insect capture in the wooded area than in the marsh but the differences were not statistically significant.

Wind direction significantly affected C. hollensis activity in the marsh but not within the wooded border; this is opposite to the findings for C. $f u$ rens. The overall effect of wind direction seemed greatest at wind velocities $<5 \mathrm{~km} / \mathrm{h}$.

For both $C$. furens and $C$. hollensis, the day-today variations in suction-trap catches were large and the measured parameters accounted for less than $1 / 2$ of this variability. Consideration of other parameters, such as relative humidity, illumination and atmospheric pressure, may help to explain 
more of the variability. To elucidate adequately all the factors affecting flight activity, controlled laboratory experiments are needed, but this is presently impractical due to the lack of simple and reliable rearing procedures for producing large numbers of these species in similar physiological states.

\section{LITERATURE CITED}

Bidlingmayer, W. L. 1961. Field activity studies of adult $\mathrm{Cu}$ licoides furens. Ann. Entomol. Soc. Am. 54: 149-56.

Breeland, S. G. \&. J. B. Smith. 1962. Observations on the importance of flight range in the control of Culicoides in the Panama Canal Zone. Mosq. News 22: 147-54.

Henry, L. G. \& T. R. Adkins. 1975. Vertical distribution of biting midges in coastal South Carolina. Ann. Entomol. Soc. Am. 68: 321-24.

Kettle, D. S. 1962. The bionomics and control of Culicoides and Leptoconops (Diptera, Ceratopogonidae $=$ Heleidae). Annu. Rev. Entomol. 7: 401-18.

1969a. The biting habits of Culicoides furens (Poey) and $C$. barbosai Wirth and Blanton. I. The 24-hr. cycle with a note on differences between collectors. Bull. Entomol. Res. 49: 21-31.

1969b. The biting habits of Culicoides furens (Poey) and $C$. barbosai Wirth and Blanton. II. Effects of meteorological conditions. Bull. Entomol. Res. 59: 241-58.

1972. The biting habits of Culicoides furens (Poey) and $C$. barbosai Wirth and Blanton. III. Seasonal cycle with a note on the relative importance of ten factors that might influence the biting rate. Bull. Entomol. Res. 61: 565-76.

1977. Biology and bionomics of bloodsucking Ceratopogonidae. Annu. Rev. Entomol. 22: 33-51.

Kettle, D. S. \& J. R. Linley. 1969a. The biting habits of some Jamaican Culicoides. I. C. barbosai Wirth and Blanton. Bull. Entomol. Res. 58: 729-53. 1969b. The biting habits of some Jamaican Culicoides. II. C. furens (Poey). Bull. Entomol. Res. 59: 1-20.

Kline, D. L. \& R. C. Axtell. 1976. Salt marsh Culicoides (Diptera: Ceratopogonidae): Species, seasonal abundance and comparisons of trapping methods. Mosq. News 36: 1-10.

1977. Distribution of Culicoides hollensis, C. furens and C. bermudensis in relation to plant cover in a North Carolina salt marsh (Diptera: Ceratopogonidae). J. Med. Entomol. 13: 545-52.

Koch, H. G., R. C. Axtell \& G. R. Baughman. 1977. A suction trap for hourly collection of coastal biting flies. Mosq. News 37: $674-80$.

Lewis, T. \& L. R. Taylor. 1965. Diurnal periodicity of flight by insects. Trans. R. Entomol. Soc. London 116: 393-476.

Linley, J. R. \& J. B. Davies. 1971. Sandflies and tourism in Florida and the Bahamas and Caribbean area. J. Econ. Entomol. 64: 264-78.

Nelson, R. L. \& R. E. Bellamy. 1971. Patterns of flight activity of Culicoides variipennis (Coquillett) (Diptera: Ceratopogonidae). J. Med. Entomol. 8: 283-91.

Reuben, R. 1963. A comparison of trap catches of Culicoides impunctatus Goetghebuer (Diptera: Ceratopogonidae) with meteorological data. Proc. R. Entomol. Soc. London (A) 38: 181-93.

Service, M. W. 1971. Adult flight activities of some British Culicoides species. J. Med. Entomol. 8: 605-09.

1974. Further results of catches of Culicoides (Diptera: Ceratopogonidae) and mosquitoes from suction traps. J. Med. Entomol. 11: 471-79.

1976. Mosquito ecology-Field sampling methods. John Wiley \& Sons, New York. 583 p.

Snow, W. E. 1955. Feeding activities of some bloodsucking Diptera with reference to vertical distribution in the bottomland forest. Ann. Entomol. Soc. Am. 48: 512-21.

Tanner, G. D. \& E. C. Turner, Jr. 1974. Vertical activities and host preferences of several Culicoides species in a southwestern Virginia forest. Mosq. News 34: 66-70. 